\title{
An Activity-based Fluorogenic Probe Enables Cellular and In Vivo Profiling of Carboxylesterase Isozymes
}

Shi-Yu Liu, ${ }^{\dagger} \S$ Ren-Yu Qu ${ }^{\dagger, \S}$ Rong-Rong Li, ${ }^{\dagger}$ Yao-Chao Yan, ${ }^{\dagger}$ Yao Sun, ${ }^{\dagger}$ Wen-Chao Yang, ${ }^{* \dagger}$ and Guang-Fu Yang ${ }^{*} \dagger *$

†Key Laboratory of Pesticide \& Chemical Biology of Ministry of Education, International Joint Research Center for Intelligent Biosensor Technology and Health, and Chemical Biology Center, College of Chemistry, Central China Normal University, Wuhan 430079, P.R. China

Collaborative Innovation Center of Chemical Science and Engineering, Tianjin 30071, P.R. China.

\section{Table of contents}

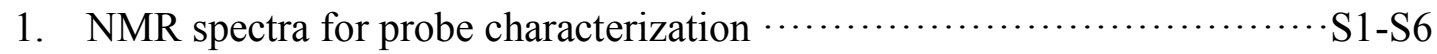

2. Additional data S7-S11

\footnotetext{
$\S$ These two authors made equal contributions.

* Wen-Chao Yang, e-mail: tomyang@mail.ccnu.edu.cn; Tel: 86-27-67867706; Fax: 86-2767867141; Guang-Fu Yang, e-mail: gfyang@mail.ccnu.edu.cn; Tel: 86-27-67867800; Fax: 86-27-67867141.
} 
1. NMR spectra for probe characterization
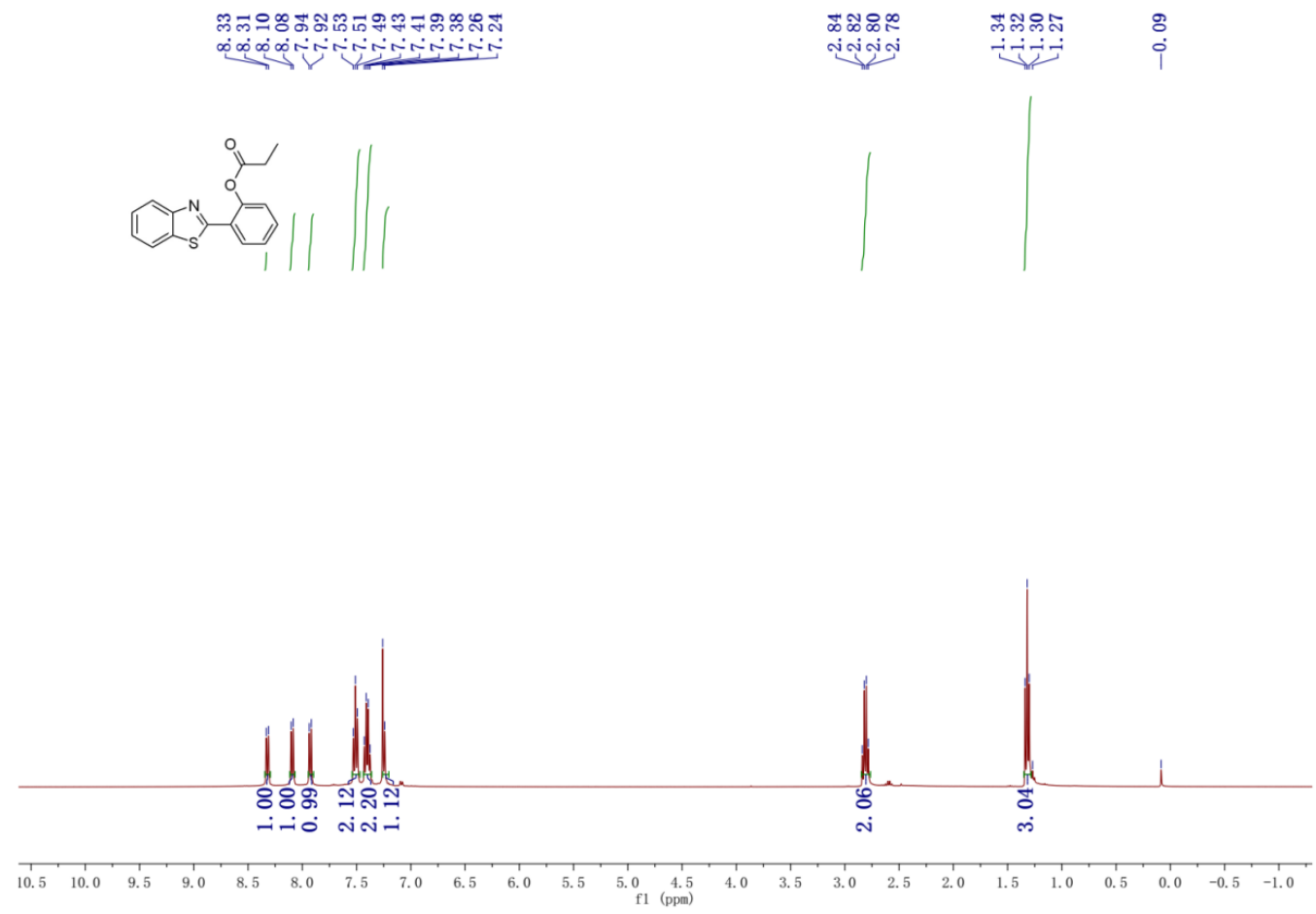

Figure S1 ${ }^{1} \mathrm{H}$ NMR for Probe 1 in $\mathrm{CDCl}_{3}$.

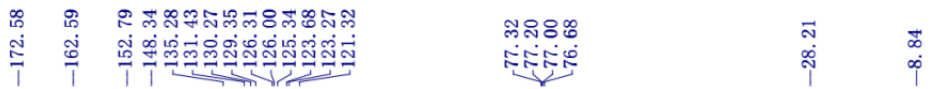
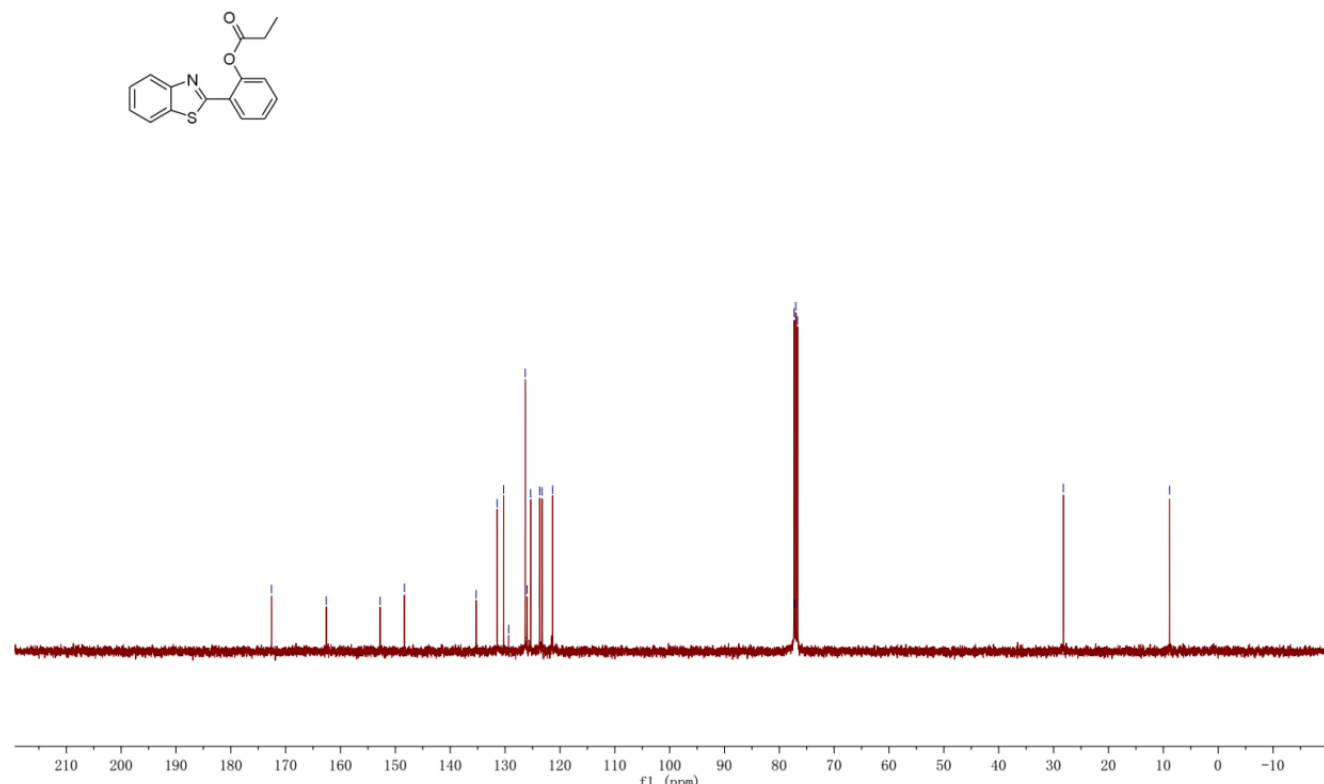

Figure S2 ${ }^{13} \mathrm{C}$ NMR for Probe 1 in $\mathrm{CDCl}_{3}$. 


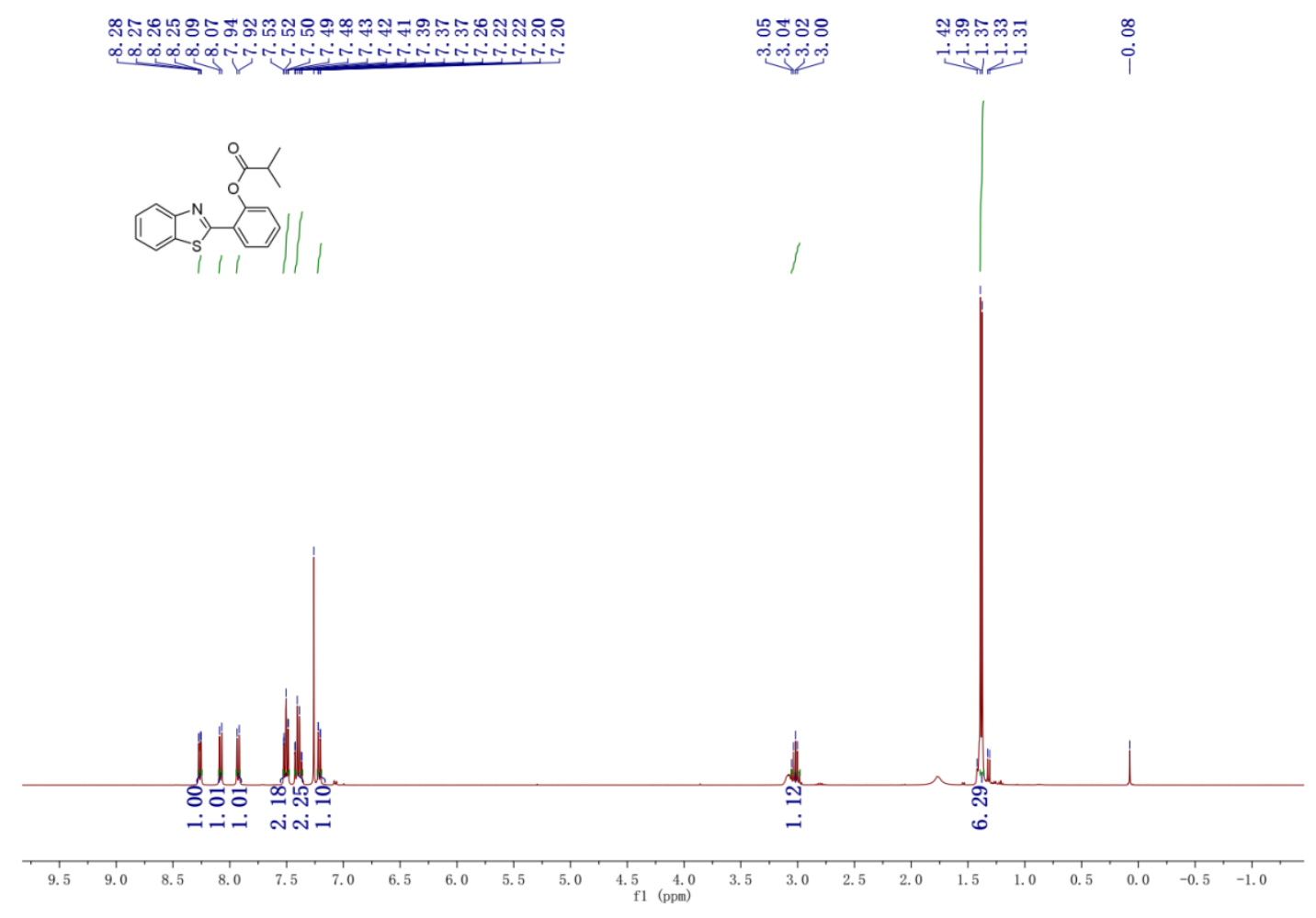

Figure $\mathbf{S 3}{ }^{1} \mathrm{H}$ NMR for Probe 2 in $\mathrm{CDCl}_{3}$.

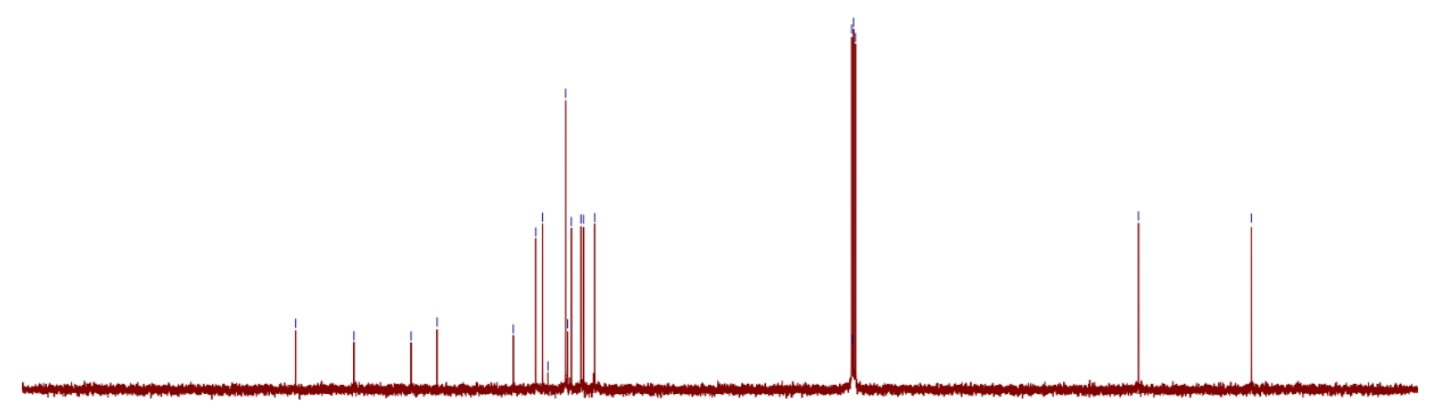

$\begin{array}{llllllllllll}210 & 200 & 190 & 180 & 170 & 160 & 150 & 140 & 130 & 120 & 110 & 100 \\ \mathrm{f} 1(\mathrm{ppm})\end{array}$

Figure $\mathrm{S} 4{ }^{13} \mathrm{C}$ NMR for Probe 2 in $\mathrm{CDCl}_{3}$. 


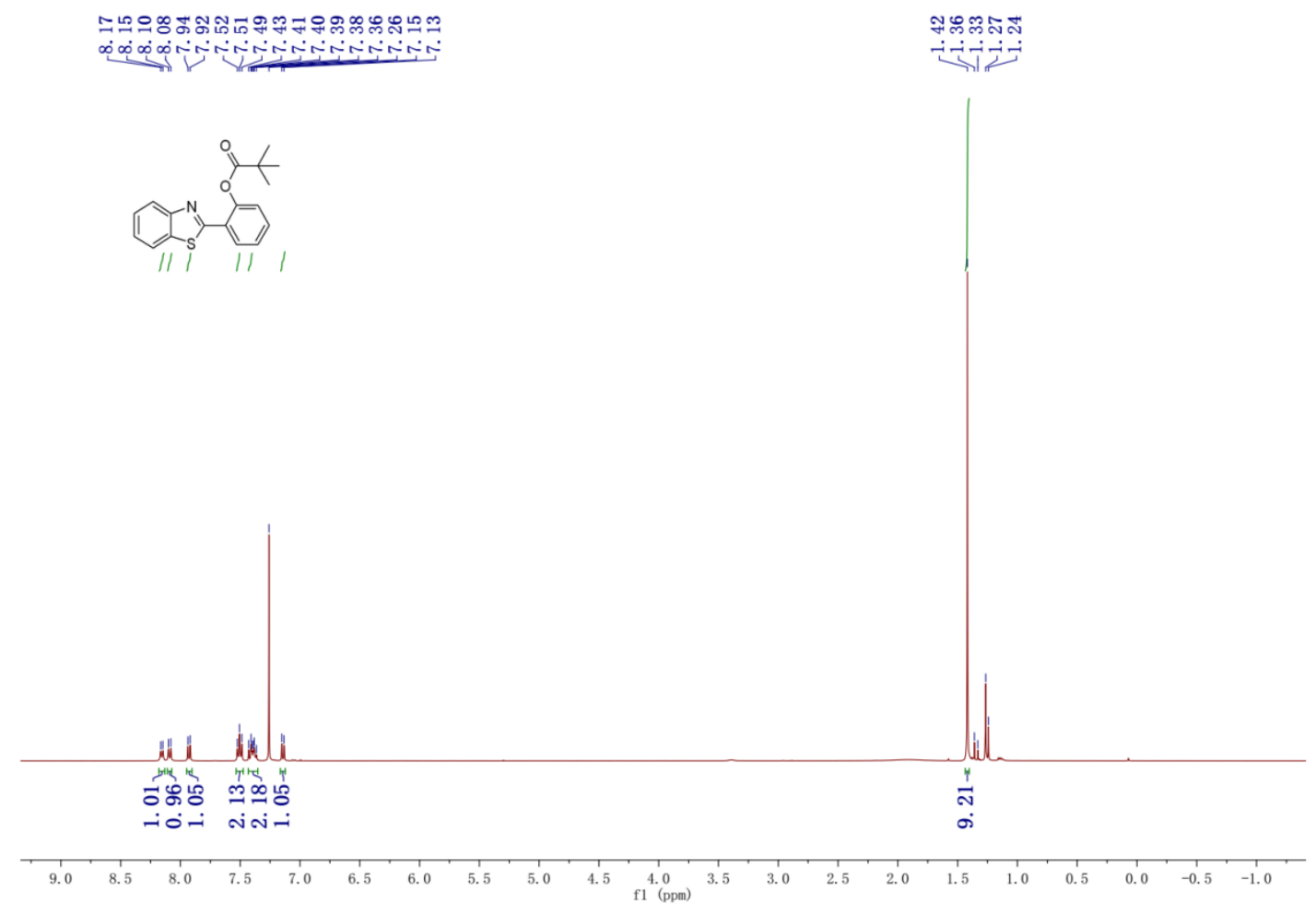

Figure S5 ${ }^{1} \mathrm{H}$ NMR for Probe 3 (HBT-CE) in $\mathrm{CDCl}_{3}$.
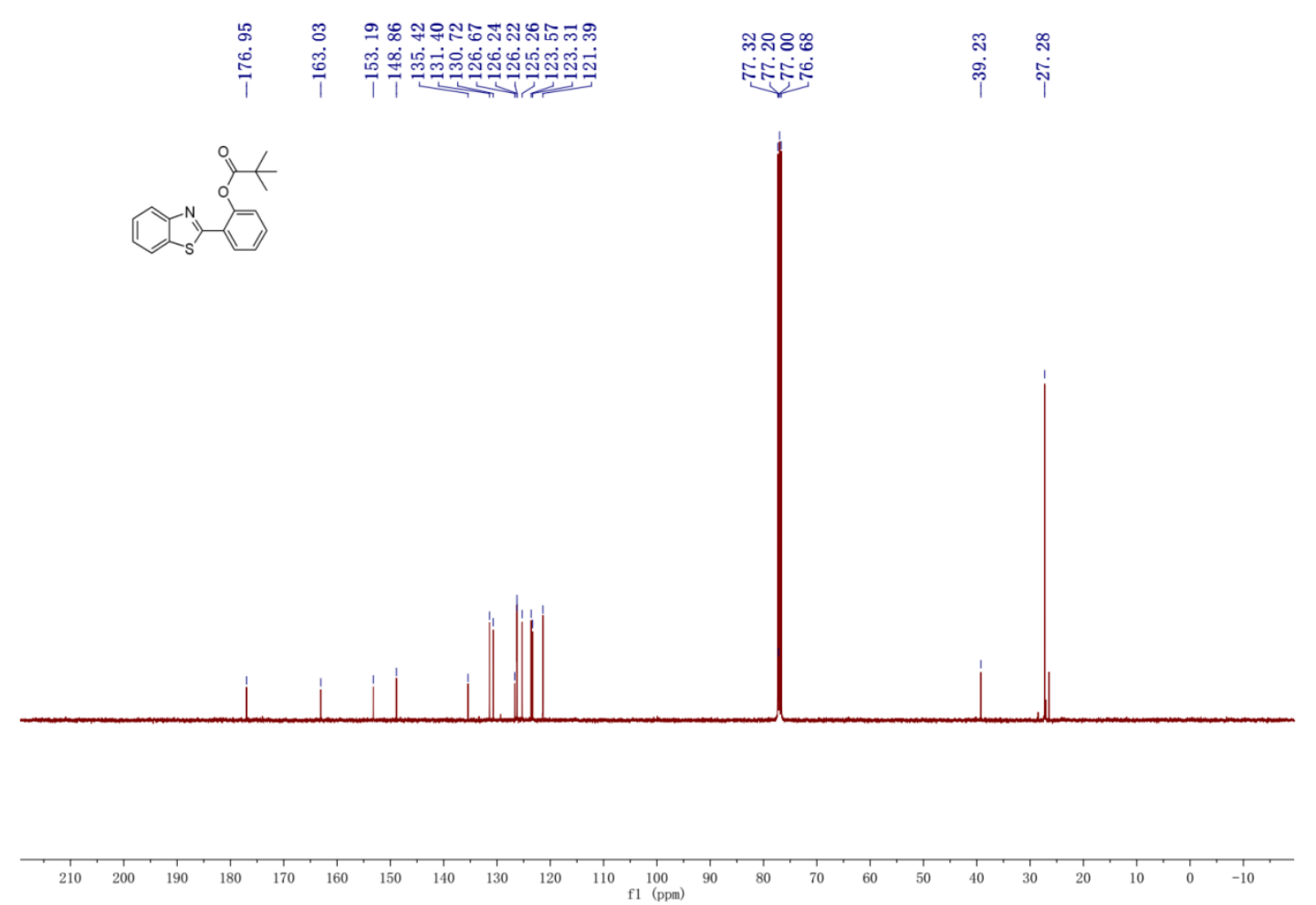

Figure S6 ${ }^{13} \mathrm{C}$ NMR for Probe 3 (HBT-CE) in $\mathrm{CDCl}_{3}$. 


\section{Additional data}
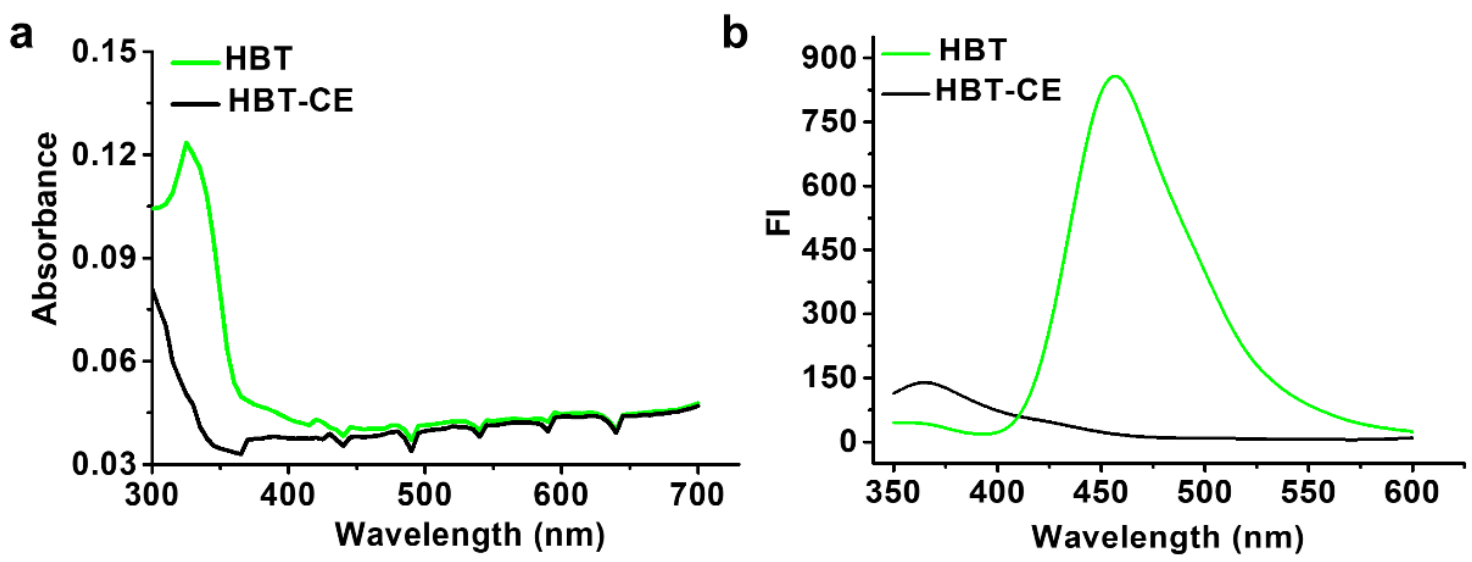

Figure S7. UV-Visible (a) and fluorescent (b) spectrum of HBT and HBT-CE $(10 \mu \mathrm{M})$.

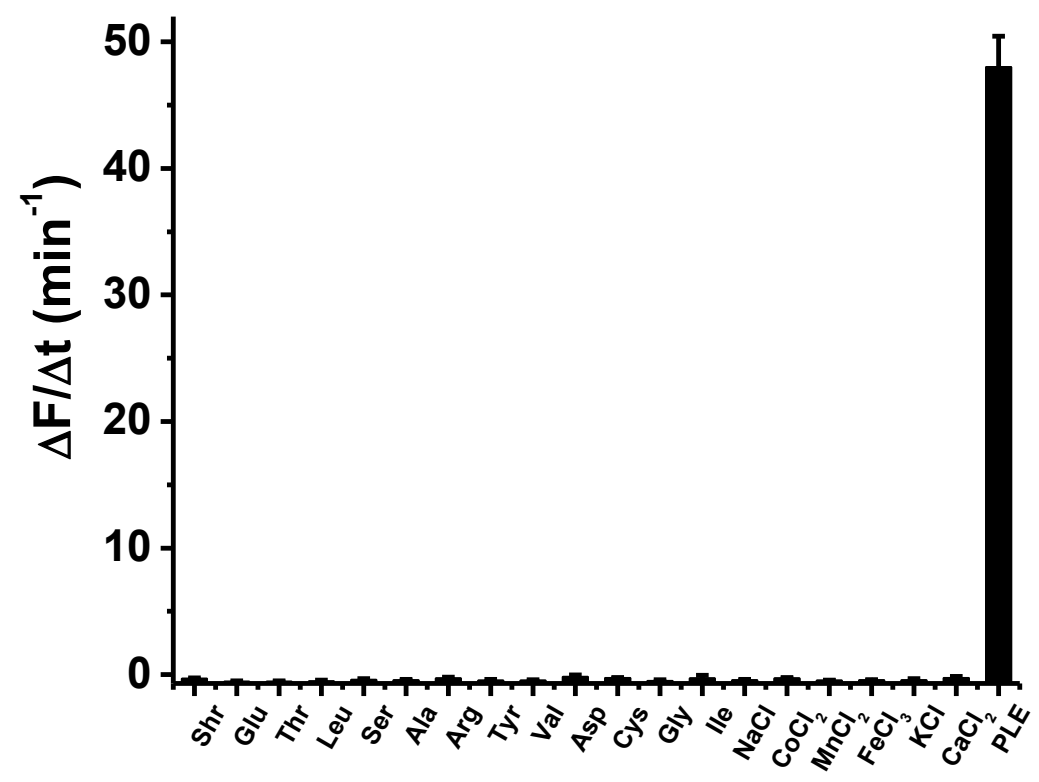

Figure S8. Fluorescence response of HBT-CE $(10 \mu \mathrm{M})$ toward various kind of small molecules (amino acids and metallic ions, $1 \mathrm{mM}$ ) compared with PLE $(0.05 \mathrm{U} / \mathrm{mL})$. 


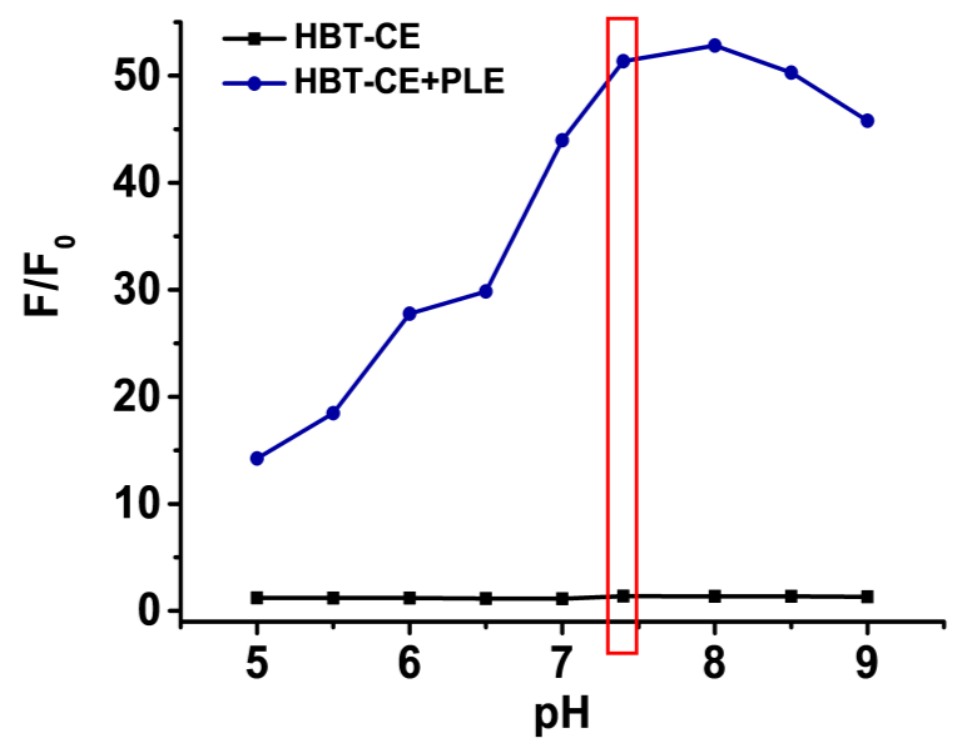

Figure S9. Fluorescence response of HBT-CE with (blue line) and without (back line) the addition of PLE at different $\mathrm{pH}$ values.

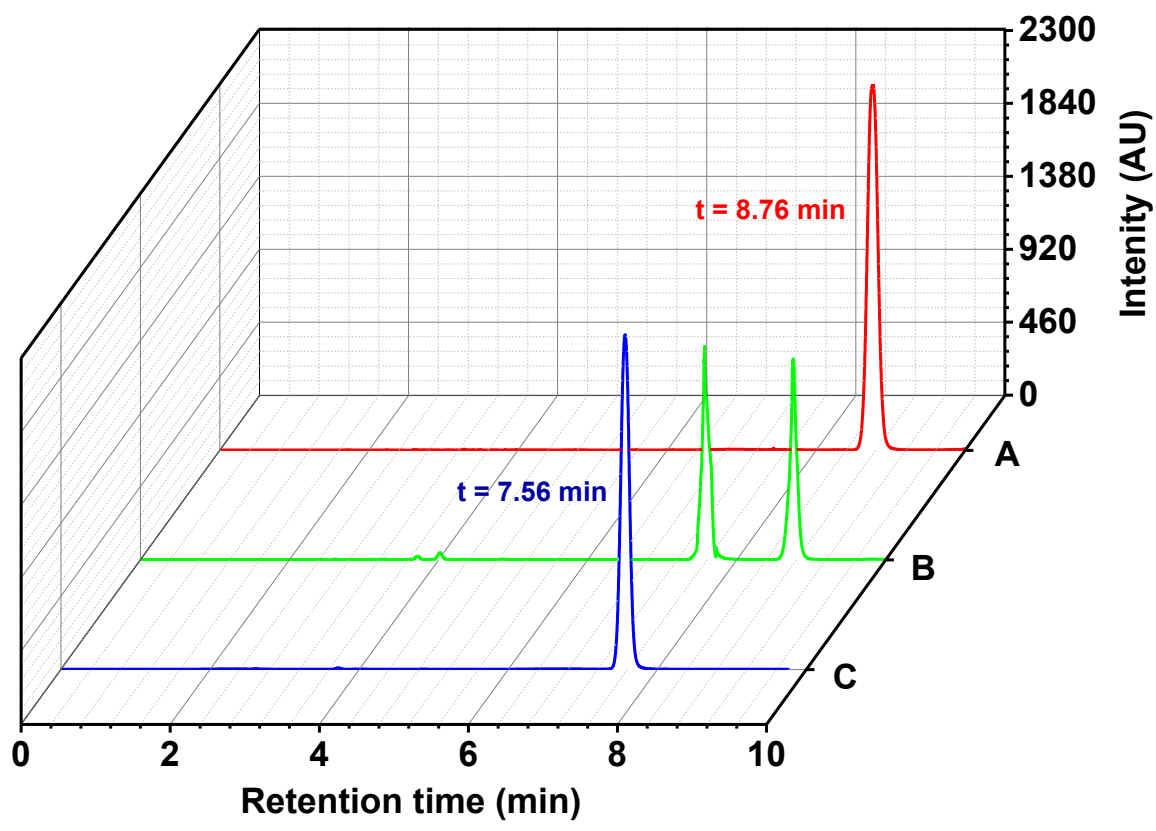

Figure S10. HPLC analysis for the hydrolysis of HBT-CE $(10 \mu \mathrm{M})$ in the absence (A for HBT$\mathbf{C E}$, in red) and presence (B for the reaction system, in green) of PLE $(1 \mu \mathrm{g} / \mathrm{mL})$ after $10 \mathrm{~min}$ incubation at $30^{\circ} \mathrm{C}$, with the fluorophore as control (C for HBT, in blue). 


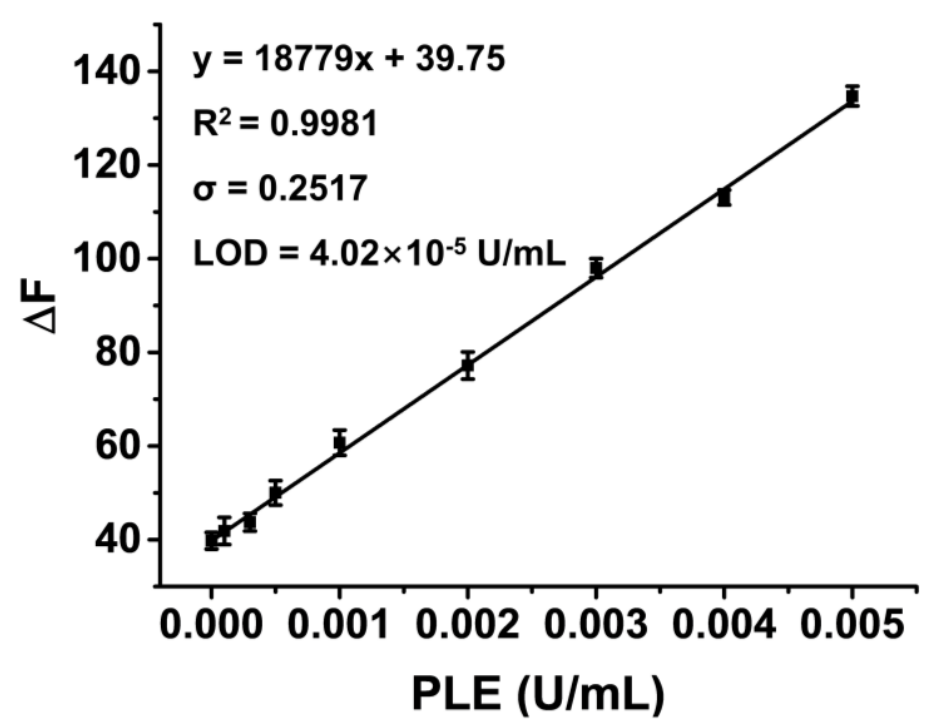

Figure S11. Linearity curve of fluorescence response of HBT-CE $(10 \mu \mathrm{M})$ toward various concentration of PLE from 0.0001 to $0.005 \mathrm{U} / \mathrm{mL}$.

\begin{tabular}{|c|c|c|c|c|c|c|}
\hline Enzyme & $K_{m}(\mu M)$ & $k_{\text {cat }}\left(\mathbf{s}^{-1}\right)$ & $\begin{array}{c}k_{\text {cat }} / K_{\mathrm{m}} \\
\left(\mathrm{M}^{-1} \cdot \mathrm{s}^{-1}\right)\end{array}$ & Structure & LOD & REF \\
\hline Human carboxylesterase 1 & $18.43 \pm 2.58$ & $3.07 \pm 0.19$ & $2.09 \times 10^{5}$ & & 1 & This work \\
\hline Human carboxylesterase 2 & $11.60 \pm 1.17$ & $1.75 \pm 0.07$ & $2.03 \times 10^{5}$ & & 1 & This work \\
\hline Porcine liver esterase & $3.06 \pm 0.14$ & $41.36 \pm 0.86$ & $1.35 \times 10^{6}$ & & $4.02 \times 10^{-5} \mathrm{U} / \mathrm{mL}$ & This work \\
\hline Horse liver esterase & 1 & 1 & 1 & & $8.6 \times 10^{-5} \mathrm{U} / \mathrm{mL}$ & 28 \\
\hline Porcine liver esterase & $4.33 \pm 0.22$ & $0.890 \pm 0.012$ & $2.10 \times 10^{5}$ & & 1 & 29 \\
\hline Porcine liver esterase & 18 & 0.47 & $2.6 \times 10^{4}$ & & $1.2 \times 10^{-4} \mathrm{U} / \mathrm{mL}$ & 30 \\
\hline Carboxylesterase $^{*}$ & 4.4 & 1 & 1 & & $1.8 \times 10^{-3} \mathrm{U} / \mathrm{mL}$ & 31 \\
\hline Porcine liver esterase & 1 & 1 & 1 & & $2.4 \times 10^{-3} \mathrm{U} / \mathrm{mL}$ & 32 \\
\hline Carboxylesterase $^{*}$ & 1 & 1 & 1 & & $4.5 \times 10^{-3} \mathrm{U} / \mathrm{mL}$ & 33 \\
\hline Carboxylesterase ${ }^{\star}$ & 1 & 1 & 1 & & $3.4 \times 10^{-3} \mathrm{U} / \mathrm{mL}$ & 34 \\
\hline
\end{tabular}

Figure S12. List and comparison of the kinetic parameters and LOD of HBT-CE with the former reported CEs probes. ${ }^{*}$. the source of the esterase was not mentioned in the literature) 


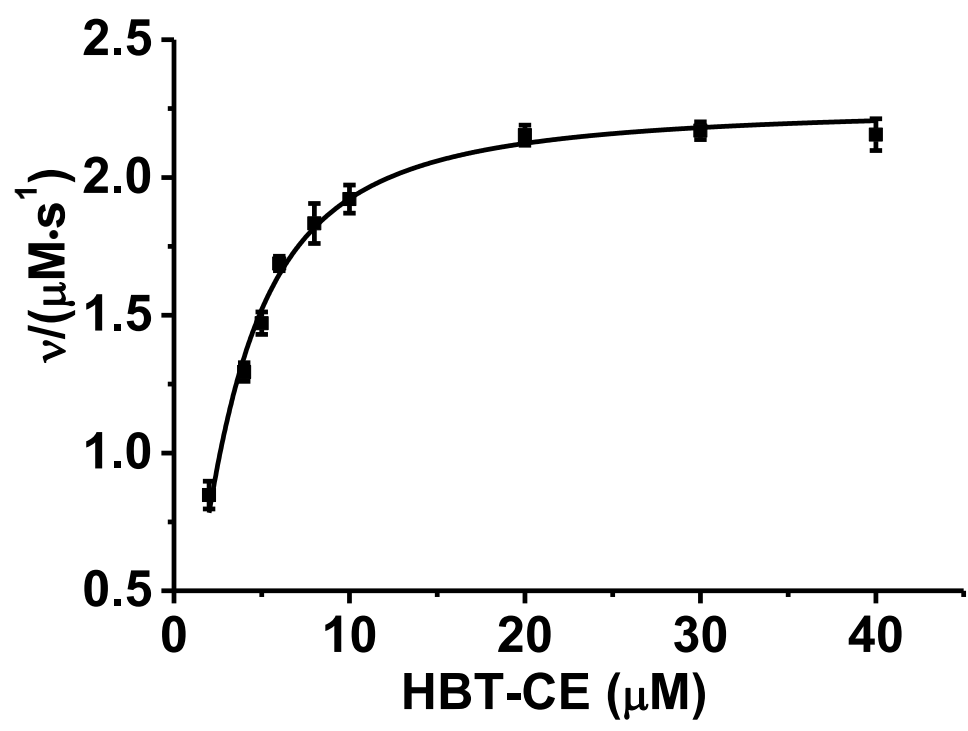

Figure S13. Michaelis-Menten curve for HBT-CE catalysis by PLE $(0.05 \mathrm{U} / \mathrm{mL})$ in phosphate buffer (10 mM, pH 7.4).

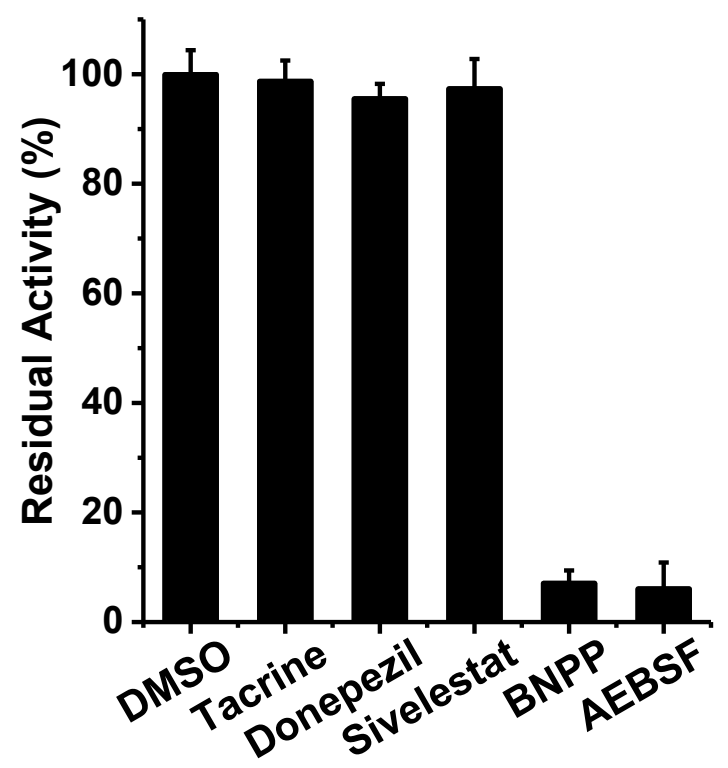

Figure S14. Detection of activity of CEs in HepG2 cells with HBT-CE $(10 \mu \mathrm{M})$, cell lysates were preincubated with tacrine $(50 \mu \mathrm{M})$, donepezil $(50 \mu \mathrm{M})$, sivelestat $(50 \mu \mathrm{M})$, BNPP $(500 \mu \mathrm{M})$, AEBSF ( $1 \mathrm{mM})$ or $0.1 \%$ DMSO as a control. 


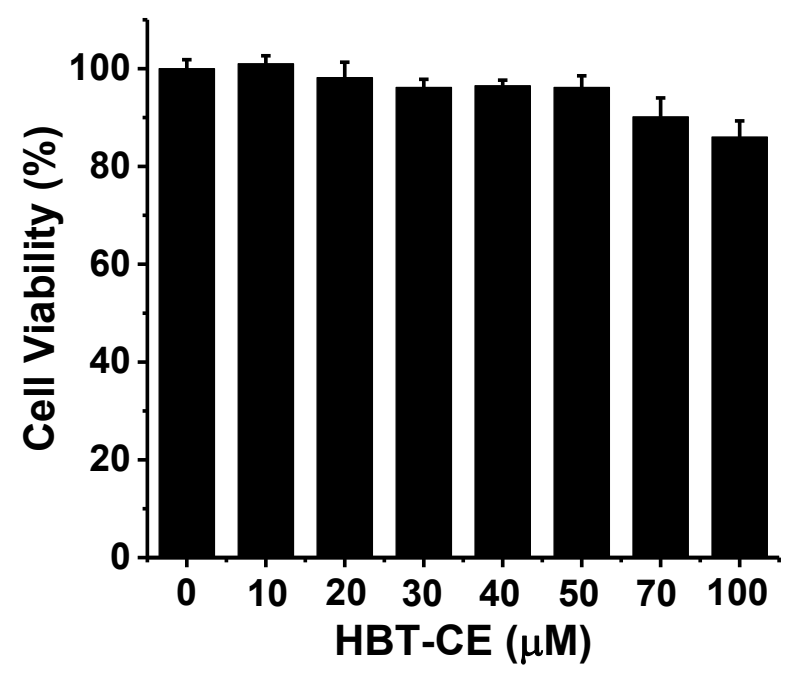

Figure S15. Cytotoxicity of HBT-CE toward Hep G2 cells at various concentration determined by MTT assay after incubated for $24 \mathrm{~h}$.

Table S1. List of the fluorescence properties of HBT and HBT-CE.

\begin{tabular}{ccccc}
\hline & $\lambda_{\mathrm{ab}}(\mathrm{nm})$ & $\lambda_{\mathrm{em}}(\mathrm{nm})$ & $\Phi$ & $\varepsilon\left(\mathrm{M}^{-1} \cdot \mathrm{cm}^{-1}\right)$ \\
\hline HBT & 325 & 460 & 0.026 & 15748 \\
HBT-CE & 280 & 370 & 0.005 & 12451 \\
\hline
\end{tabular}

